\title{
Gastric involvement, a rare site for extramedullary myeloma
}

\author{
Yoshiharu Kusano $^{1}$ - Noriko Nishimura ${ }^{1} \cdot$ Masahiro Yokoyama $^{1} \cdot$ Yasuhito Terui $^{1}$. \\ Kiyohiko Hatake ${ }^{1}$
}

Received: 16 November 2015 / Accepted: 3 January 2016/Published online: 12 January 2016

(C) The Author(s) 2016. This article is published with open access at Springerlink.com

\section{Abbreviations \\ MM Multiple myeloma \\ BD Bortezomib plus dexamethasone}

\section{Dear Editor,}

Gastric involvement of multiple myeloma (MM) is rare. It accounts for $7 \%[1,2]$ of total extramedullary plasmacytomas. Patients with MM present gastric carcinoma in $3 \%$ of cases. We present here a case that gastric involvement of MM was diagnosed soon after endoscopic submucosal dissection against gastric carcinoma.

A 64-year-old man was referred for further evaluation of renal impairment, hypercalcemia, and anemia. His general condition was scored 3 according to EOCG performance status. Physical examination showed dry skin and pallor conjunctiva. Both serum and urine immunofixation electrophoresis revealed monoclonal $\mathrm{IgG}$ elevation and lambda chain restriction. Bone marrow aspirate showed an infiltration of $60 \%$ monoclonal plasma cells. Positron emission tomography showed numerous bone fractures. Based on these results, the diagnosis of symptomatic MM was confirmed. On the other hand, early-stage gastric adenocarcinoma was found coincidentally. Treatment priority was put on MM, and he started on chemotherapy with bortezomib plus dexamethasone (BD). Efficacy of BD was observed gradually; however, he experienced numerous infectious events. First, he suffered from a

Yoshiharu Kusano

yoshiharu.kusano@jfcr.or.jp

1 Department of Hematology and Oncology, The Cancer Institute Hospital of Japanese Foundation for Cancer Research, 3-8-31, Ariake, Koto-ward, Tokyo 135-8550, Japan cytomegalovirus (CMV) infection. He usually presented diarrhea after bortezomib administration. Although diarrhea usually stopped in several days, diarrhea occurring 10 times per day sometimes continued for a week. He also presented fatigue due to volume depletion and was admitted. Laboratory test showed elevated CMV IgM. And CMV retinitis was also diagnosed. Gancyclovir $5 \mathrm{mg} / \mathrm{kg}$ per $12 \mathrm{~h}$ was administered. Following a total of 14 days administration, CMV retinitis and gastroenteritis were completely cured without any complications. Second, Clostridium difficile (CD) toxin was found, associated with gastroenteritis. When he complained of a sore throat at another clinic, the physician prescribed antibiotics. He presented with diarrhea as usual after bortezomib administration, but his diarrhea did not disappear for a week. CD toxin was verified and diarrhea ended by vancomycin, which was continued for 10 days. The third was a varicella virus infection due to immunosuppression caused by bortezomib.

When the seventh cycle of BD was finished, he achieved partial response, but the amount of $\mathrm{M}$ protein gradually increased with many postponements of BD. Endoscopic submucosal dissection was performed and gastric cancer was removed completely. However, 1 month later, multiple bull's-eye lesions emerged in the greater curvature of the stomach (Fig. 1a, indigo carmine staining), found during a routine checkup. Pathological findings confirmed plasmacytoma (b, hematoxylin and eosin staining; c, highlighted with lambda chain staining; $d$, highlighted with CD138 staining). At that time, he became ineligible for a transplant due to his age and instead was supposed to receive bortezomib, melphalan, and dexamethasone (VMP). Nevertheless, he eventually died of acute coronary syndrome.

Prior study showed only $0.9 \%$ had gastric involvement in $2584 \mathrm{MM}$ patients [3]. Our case had gastric carcinoma coincidently. Kyle reviewed $869 \mathrm{MM}$ patients and concluded that $3 \%$ had other kinds of solitary tumors [4]. Especially, several cases in which MM and gastric cancer were diagnosed 
Fig. 1 Endoscopic appearance and histological appearance of plasma cell myeloma in gastric biopsy (a indigo carmine staining, b hematoxylin and eosin staining, c highlighted with lambda chain staining, $\mathbf{d}$ highlighted with CD138 staining)

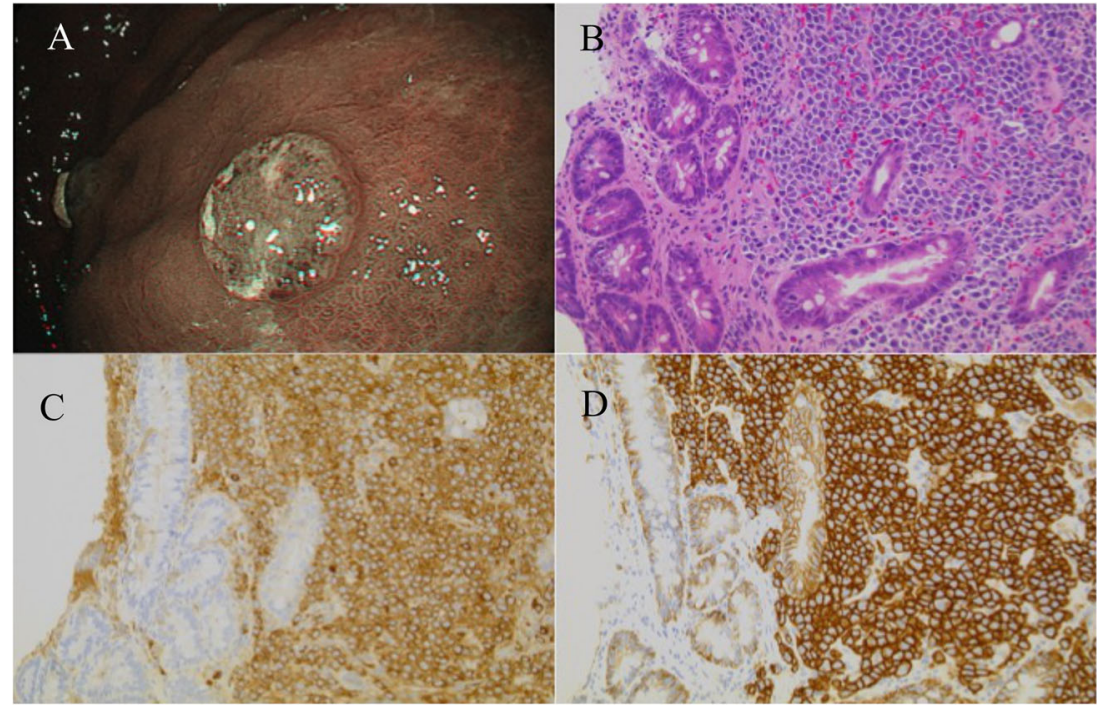

together were reported from Japan, a country with a high prevalence of gastric cancer [5-7]. This case in which gastric involvement of MM is, however, found within a short period after removal of gastric carcinoma is first report, to the best our knowledge, even in Japan.

\section{Compliance with ethical standards}

Conflict of interest The authors declare that they have no conflict of interest.

Open Access This article is distributed under the terms of the Creative Commons Attribution 4.0 International License (http:// creativecommons.org/licenses/by/4.0/), which permits unrestricted use, distribution, and reproduction in any medium, provided you give appropriate credit to the original author(s) and the source, provide a link to the Creative Commons license, and indicate if changes were made.

\section{References}

1. Alexiou C, RJ K a, Dietzfelbinger H et al (1999) Extramedullary plasmacytoma: tumor occurrence and therapeutic concepts. Cancer 85:2305-2314

2. Dolin S, Dewer J (1955) Extramedullary plasmacytoma. Am J Pathol 32:83-103

3. Talamo G, Cavallo F, Zangari M et al (2006) Clinical and biological features of multiple myeloma involving the gastrointestinal system. Haematologica 91:964-967

4. Kyle RA (1975) Multiple myeloma: review of 869 cases. Mayo Clin Proc 50:29-40

5. Matsushita S, Matsuzaki H, Kawano F et al (1984) A case of nonsecretory myeloma (accompanied with gastric carcinoma) analyzed with plaque forming cell assay. Rinsho Ketsueki 25:393-398

6. Yasuma A, Nakashima I, Muramatsu M et al (1973) A case of multiple myeloma associated with operated stomach cancer. Rinsho Ketsueki 14:714-720

7. Yamada O, Naito T, Shimazaki M et al (1993) A case of multiple myeloma complicated with early gastric cancer and early sigmoid colon cancer. Nippon Shokakibyo Gakkai Zasshi 90:1432-1436 